\title{
PROLOGUE
}

\section{A Victorian Perspective on Globalization}

... we have now reached the third stage in our history, and the true conception of our Empire.

What is that conception? As regards the self-governing colonies we no longer talk of them as dependencies. The sense of possession has given place to the sense of kinship. We think and speak of them as part of ourselves, as part of the British Empire, united to us, although they may be dispersed throughout the world, by ties of kindred, of religion, of history, and of language, and joined to us by the seas that formerly seemed to divide us. But the British Empire is not confined to the self-governing colonies and the United Kingdom. It includes a much greater area, a much more numerous population in tropical climes, where no considerable European settlement is possible, and where the native population must always outnumber the white inhabitants ... Here also the sense of possession has given way to a different sentiment - the sense of obligation. We feel now that our rule over these territories can only be justified if we can show that it adds to the happiness and prosperity of the people... 
In carrying out this work of civilization we are fulfilling what I believe to be our national mission, and we are finding scope for the exercise of those faculties and qualities which have made us a great governing race...

No doubt, in the first instance, when those conquests have been made, there has been bloodshed, there has been loss of life among the native populations, loss of still more precious lives among those who have been sent out to bring these countries into some kind of disciplined order [but] ... You cannot have omelettes without breaking eggs; you cannot destroy the practices of barbarism, of slavery, of superstition, which for centuries have desolated the interior of Africa, without the use of force ... Great is the task, great is the responsibility, but great is the honour: and I am convinced that the conscience and the spirit of the country will rise to the height of its obligations, and that we shall have the strength to fulfil the mission which our history and our national character have imposed upon us.

... the tendency of the time is to throw all power into the hands of the greater empires ... But, if Greater Britain remains united, no empire in the world can ever surpass it in area, in population, in wealth, or in the diversity of its resources ...

Extracts from a speech by Joseph Chamberlain, Secretary of State for the Colonies, at the annual dinner of the Royal Colonial Institute, 